\title{
Prediction and optimization of weld bead geometry in gas metal arc welding process using RSM and fmincon
}

\author{
P. Sreeraj ${ }^{1 \star}$, T. Kannan ${ }^{2}$ and Subhasis Maji ${ }^{3}$ \\ ${ }^{1}$ Department of Mechanical Engineering, Valia Koonambaikulathamma College of \\ Engineering Technology, Kerala, 692574 India. \\ ${ }^{2}$ SVS College of Engineering, Coimbatore, Tamilnadu, 642109 India. \\ ${ }^{3}$ Department of Mechanical Engineering IGNOU, Delhi, 110068, India.
}

Accepted 27 September, 2013

\begin{abstract}
Cladding is a surface modification process in which a specially designed alloy is surface welded in order to enhance corrosion resistant properties. Common cladding techniques include Gas Tungsten Arc Welding (GTAW), submerged arc welding (SAW) and gas metal arc welding (GMAW). Because of high reliability, easiness in operation, high penetration good surface finish and high productivity gas metal arc welding became a natural choice for fabrication industries. This paper presents central composite rotatable design with full replication techniques to predict four critical dimensions of bead geometry. The second order regression method was developed to study the correlations. The developed models have been checked for adequacy and significance. The main and interaction effects of process variables and bead geometry were presented in graphical form. Using fmincon function the process parameters were optimized.
\end{abstract}

Key words: Gas metal arc welding (GMAW), weld bead geometry, mathematical model.

\section{INTRODUCTION}

Excessive research work has been performed in Gas Metal Arc Welding process. Even though much literature is available on cladding of stainless steels, no systematic research works so far to correlate the process parameters with dilution. It is the amount of base metal melted (B) divided by the sum of filler metal added and base metal added $(A+B)$. This is shown in Figure 1 . Dilution reduces the alloying elements and increases the carbon content in the clad layer. This reduces the corrosion resistance properties and causes other metallurgical problems in welding (kannan and Murugan, 2006). So it is necessary to study the effects of dilution in bead parameters. It is also known that the quality of a weld and dilution depends on mechanical properties of the weld metal which in turn depends on metallurgical characteristics and chemical composition of the weld. The mechanical and metallurgical feature of weld depends on bead geometry which is directly related to welding process parameters. In other words quality of weld depends on in process parameters. GMA welding is a multi objective and multifactor metal fabrication technique. The process parameters have a direct influence on bead geometry which in turn affects dilution. Figure 1 shows the clad bead geometry. Mechanical strength of clad metal is highly influenced by the composition of metal but also by clad bead shape. This is an indication of bead geometry. It mainly depends on wire feed rate, welding speed, arc voltage etc. Therefore, it is necessary to study the relationship between in process parameters and bead parameters to study clad bead geometry.

This paper highlights the study carried out to develop 


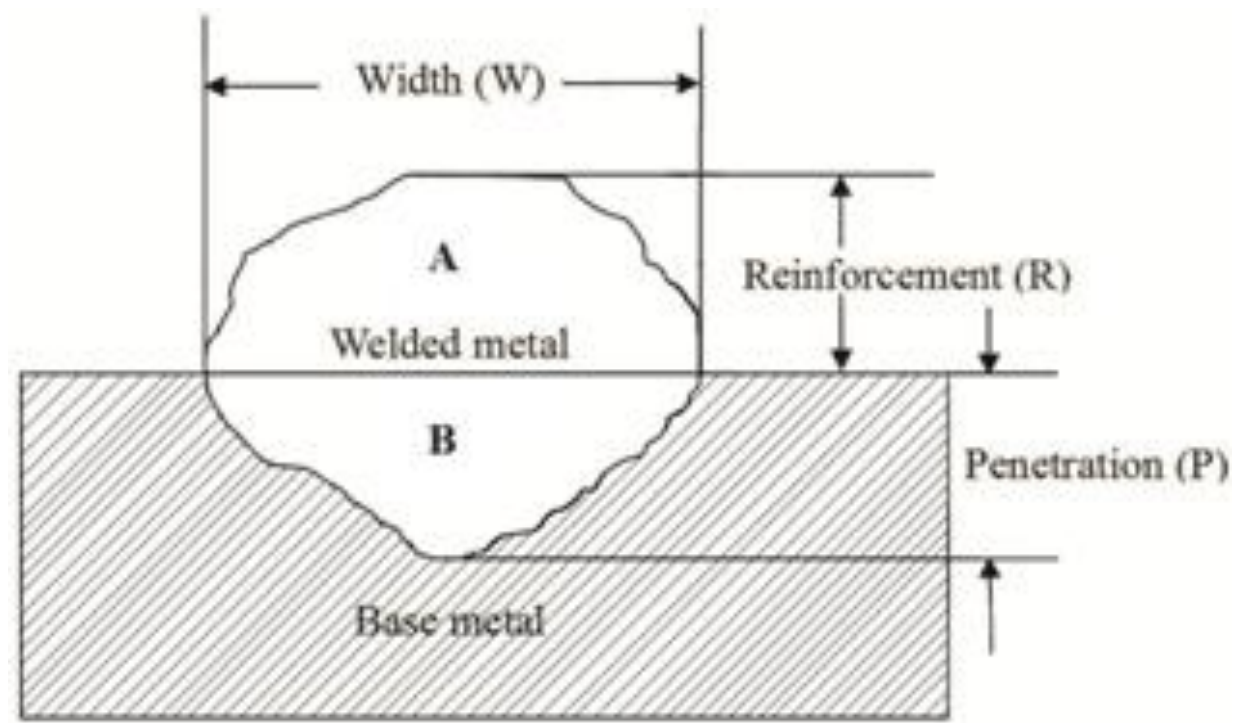

Figure 1. Clad bead geometry. Percentage dilution $(D)=[B /(A+B)] \times 100$.

mathematical, models to predict clad bead geometry, in stainless steel cladding deposited by GMAW (Kannan and Murugan, 2006).

\section{EXPERIMENTATION}

The following machines and consumables were used for conducting the experiment:

1) A constant current gas metal arc welding machine (Invrtee $V 350$ - PRO advanced processor with 5 to 425 amps output range).

2) Welding manipulator.

3) Wire feeder (LF - 74 model).

4) Filler material stainless steel wire of $1.2 \mathrm{~mm}$ diameter (ER - 308 L).

5) Gas cylinder containing a mixture of $98 \%$ argon and $2 \%$ of oxygen.

6) Mild steel plate (grade IS - 2062).

Test plates of size $300 \times 200 \times 20 \mathrm{~mm}$ were cut from mild steel plate of grade IS - 2062 and one of the surfaces is cleaned to remove oxide and dirt before cladding. ER-308 L stainless steel wire of $1.2 \mathrm{~mm}$ diameter was used for depositing the clad beads through the feeder. Argon gas at a constant flow rate of $16 \mathrm{~L}$ per minute was used for shielding (Gunaraj and Murugan, 2005). The properties of base metal and filler wire are shown in Table 1. The important and most difficult parameter found from trial run is wire feed rate. The wire feed rate is proportional to current. Wire feed rate must be greater than critical wire feed rate to achieve pulsed metal transfer. The relationship found from trial run is shown in Equation 1. The formula derived is shown in Figure 2:

Wire feed rate $=0.96742857{ }^{*}$ Current +79.1

The selection of the welding electrode wire based on matching the mechanical properties and physical characteristics of the base metal, weld size and existing electrode inventory (Kim et al., 2003). A candidate material for cladding which has excellent corrosion resistance and weld ability is stainless steel. These have chloride stress corrosion cracking resistance and strength significantly greater than other materials. These have good surface appearance, good radiographic standard quality and minimum electrode wastage. Experimental design used for this study is shown in Figure 3 and important steps are briefly explained.

\section{PLAN OF INVESTIGATION}

The research work is carried out in the following steps (Cochran and Coxz, 1987): Identification of factors, finding the limit of process variables, development of design matrix, conducting experiments as per design matrix, recording responses, development of mathematical models, checking adequacy of developed models and predicting the parameters.

\section{Identification of factors and responses}

The basic difference between welding and cladding is the percentage of dilution. The properties of the cladding is the significantly influenced by dilution obtained. Hence, control of dilution is important in cladding where a low dilution is highly desirable. When dilution is quite low, the final deposit composition will be closer to that of filler material and hence corrosion resistant properties of cladding will be greatly improved. The chosen factors have been selected on the basis to get minimal dilution and optimal clad bead geometry (Kannan and Murugan, 2006). These are wire feed rate $(\mathrm{W})$, welding speed $(\mathrm{S})$, welding gun angle $(\mathrm{T})$, contact tip to work to. The following independently controllable process parameters were found to be affecting output parameters; distance $(\mathrm{N})$ and pinch $(\mathrm{Ac})$, the responses chosen were clad bead width $(W)$, height of reinforcement $(R)$, depth of penetration $(P)$ and percentage of dilution (D). The responses were chosen based on the impact of parameters on final composite model.

\section{Finding the limits of process variables}

Working ranges of all selected factors are fixed by conducting trial 
Table 1. Chemical composition of base metal and filler wire.

\begin{tabular}{|c|c|c|c|c|c|c|c|c|c|}
\hline \multicolumn{10}{|c|}{ Elements (weight \%) } \\
\hline Materials & C & SI & Mn & $\mathbf{P}$ & S & Al & $\mathrm{Cr}$ & Mo & $\mathrm{Ni}$ \\
\hline IS 2062 & 0.150 & 0.160 & 0.870 & 0.015 & 0.016 & 0.031 & - & - & - \\
\hline ER308L & 0.03 & 0.57 & 1.76 & 0.021 & 1.008 & - & 19.52 & 0.75 & 10.02 \\
\hline
\end{tabular}

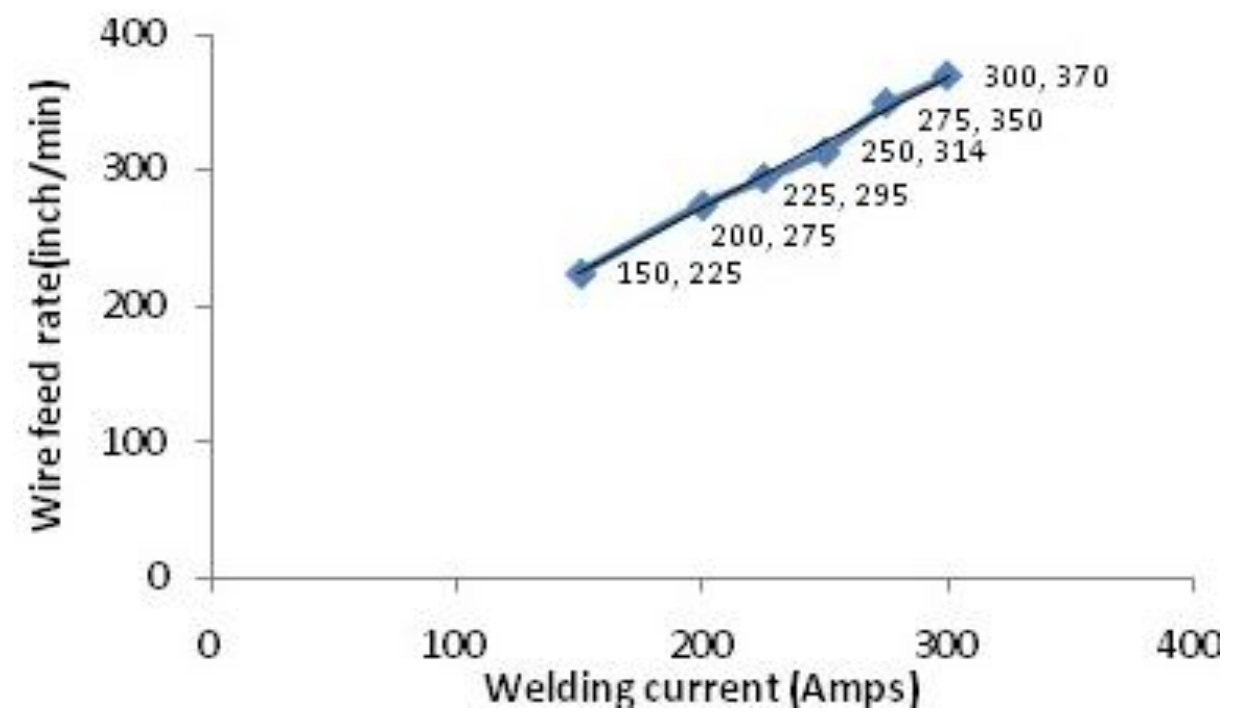

Figure 2. Relationship between current and wire feed rate.

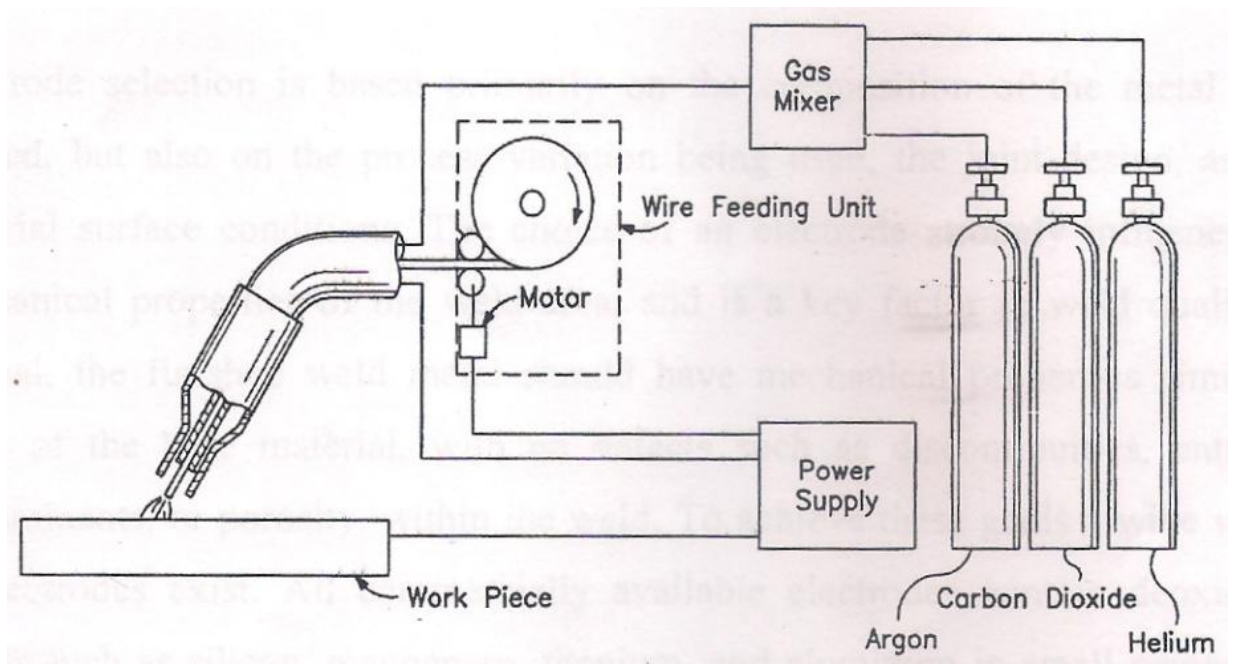

Figure 3. GMAW circuit diagram.

run. This was carried out by varying one of factors while keeping the rest of them as constant values. Working range of each process parameters was decided upon by inspecting the bead for smooth appearance without any visible defects. The upper limit of given factor was coded as -2 . The coded value of intermediate values was calculated using the Equation 2:
$X_{\mathrm{i}}=\frac{2\left[2 X-\left(X_{\max }{ }^{\left.\left.+X_{\min }\right)\right]}\right.\right.}{\left.\left[X_{\max }-X_{\min }\right)\right]}$

Where $X_{i}$ is the required coded value of parameter $X$ is any value of parameter from $X_{\min }-X_{\max } . X_{\min }$ is the lower limit of parameters and 
$\mathrm{X}_{\max }$ is the upper limit parameters (Kim et al., 2003).

The chosen level of the parameters with their units and notation are given in Table 2 .

\section{Development of design matrix}

Design matrix chosen to conduct the experiments was central composite rotatable design. The design matrix comprises of full replication of $2^{5}(=32)$, factorial designs. All welding parameters in the intermediate levels (0) constitute the central points and combination of each welding parameters at either its highest value $(+2)$ or lowest $(-2)$ with other parameters of intermediate levels $(0)$ constitute star points. 32 experimental trails were conducted that make the estimation of linear quadratic and two way interactive effects of process parameters on clad geometry (Cochran and Coxz, 1987).

\section{Conducting experiments as per design matrix}

In this work, thirty two experimental run were allowed for the estimation of linear quadratic and two-way interactive effects correspond each treatment combination of parameters on bead geometry as shown in Table 3 at random. At each run, settings for all parameters were disturbed and reset for next deposit. This is very essential to introduce variability caused by errors in experimental set up. The experiments were conducted at SVS College of Engineering, Coimbatore, 642109, India.

\section{Recording of responses}

For measuring the clad bead geometry, the transverse section of each weld overlays was cut using band saw from mid length. Position of the weld and end faces were machined and grinded. The specimen and faces were polished and etched using a $5 \%$ nital solution to display bead dimensions. The clad bead profiles were traced using a reflective type optical profile projector at a magnification of $\mathrm{X} 10$, in M/s Roots Industries Ltd. Coimbatore. Then the bead dimension such as depth of penetration height of reinforcement and clad bead width were measured (Serdar and Abdullah, 2008). The profiles are traced using AUTO CAD software. This is shown in Figure 4. This represents profile of the specimen (front side). The cladded specimen is shown in Figure 5. The measured clad bead dimensions and percentage of dilution is shown in Table 4.

\section{Development of mathematical models}

The response function representing any of the clad bead geometry can be expressed as (Ghosh et al., 1998; Gunaraj and Murugan, 1999; Montgomery, 2003):

$Y=f(A, B, C, D, E)$

Where $\mathrm{Y}=$ Response variable, $\mathrm{A}=$ welding current $(\mathrm{I})$ in amps, $\mathrm{B}=$ welding speed $(S)$ in $\mathrm{mm} / \mathrm{min}, \mathrm{C}=$ contact tip to work distance $(\mathrm{N})$ in $\mathrm{mm}, \mathrm{D}=$ welding gun angle $(\mathrm{T})$ in degrees, $\mathrm{E}=$ pinch $(\mathrm{Ac})$.

The second order surface response model equals can be expressed as:

$Y=\beta_{0}+\sum_{i=0}^{5} \beta_{i} X_{i}+\sum_{i=0}^{5} \beta_{i i} X_{i}^{2}+\sum_{i=0}^{5} \beta_{i j} X_{i} X_{j}$
$Y=\beta_{0}+\beta_{1} A+\beta_{2} B+\beta_{3} C+\beta_{4} D+\beta_{5} E+\beta_{11} A^{2}+\beta_{22} B^{2}+\beta_{33} C^{2}+$ $\beta_{44} D^{2}+\beta_{55} E^{2}+\beta_{12} A B+\beta_{13} A C+\beta_{14} A D+\beta_{15} A E+\beta_{23} B C+\beta_{24}$ $B D+\beta_{25} B E+\beta_{34} C D+\beta_{35} C E+\beta_{45} D E$

Where $\beta_{0}$ is the free term of the regression equation, the coefficient $\beta_{1}, \beta_{2}, \beta_{3}, \beta_{4}$ and $\beta_{5}$ are linear terms, the coefficients $\beta_{11}, \beta_{22}, \beta_{33}, \beta_{44}$ and $\beta_{55}$ quadratic terms, and the coefficients $\beta_{12}, \beta_{13}, \beta_{14}, \beta_{15}$, etc are the interaction terms.

The coefficients were calculated by using MINITAB 15. After determining the coefficients, the mathematical models were developed. The developed mathematical models are given as follows:

$\left.\beta_{0}=0.166338\left(\sum X_{0} Y\right)+0.05679\left(\sum \sum X_{\mathrm{in}} Y\right)\right)$

$\beta_{\mathrm{i}}=0.166338\left(\sum X_{\mathrm{i}} Y\right)$

$\beta_{\mathrm{ii}}=0.0625\left(\left(\sum X_{\mathrm{ii}} Y\right)+0.06889\left(\sum \sum X_{\mathrm{ii}} Y\right)-0.056791\left(\sum \sum X_{0} Y\right)\right)$

$\beta_{i j}=0.125\left(\sum X_{i j} Y\right)$

Clad bead width $(\mathrm{W}), \mathrm{mm}=8.923+0.701 \mathrm{~A}+0.388 \mathrm{~B}+0.587 \mathrm{C}+$ $0.040 D+0.088 E-0.423 A^{2}-0.291 B^{2}-0.338 C^{2}-0.219 D^{2}-$ $0.171 \mathrm{E}^{2}+0.205 \mathrm{AB}+0.405 \mathrm{AC}+0.105 \mathrm{AD}+0.070 \mathrm{AE}-0.134 \mathrm{BC}+$ $0.225 B D+0.098 B E+0.26 C D+0.086 C E+0.012 D E$

Depth of penetration $(P), m m=2.735+0.098 A-0.032 B+0.389 C$ $-0.032 D-0.008 E-0.124 A^{2}-0.109 B^{2}-0.125 C^{2}-0.187 D^{2}-$ $0.104 E^{2}-0.33 A B+0.001 A C+0.075 A D+0.005 A E-0.018 B C+$ $0.066 \mathrm{BD}+0.087 \mathrm{BE}+0.058 \mathrm{CD}+0.054 \mathrm{CE}-0.036 \mathrm{DE}$

Height of reinforcement $(\mathrm{R}), \mathrm{mm}=5.752+0.160 \mathrm{~A}-0.151 \mathrm{~B}-0.060 \mathrm{C}$ $+0.016 D-0.002 E+0.084 A^{2}+0.037 B^{2}-0.0006 C^{2}+0.015 D^{2}-$ $0.006 E^{2}+0.035 A B+0.018 A C-0.008 A D-0.048 A E-0.024 B C-$ $0.062 B D-0.003 B E+0.012 C D-0.092 C E-0.095 D E$

Percentage dilution (D), $\%=19.705+0.325 \mathrm{~A}+0.347 \mathrm{~B}+3.141 \mathrm{C}-$ $0.039 D-0.153 E-1.324 A^{2}-0.923 B^{2}-1.012 C^{2}-1.371 D^{2}-$ $0.872 E^{2}-0.200 A B+0.346 A C+0.602 A D+0.203 A E+0.011 B C+$ $0.465 \mathrm{BD}+0.548 \mathrm{BE}+0.715 \mathrm{CD}+0.360 \mathrm{CE}+0.137 \mathrm{DE}$

Coefficient of the aforementioned polynomial equation where calculated by regression as given by Equations 5 to 8 .

\section{Checking the adequacy of the developed models}

Analysis of variance (ANOVA) technique was used to test the adequacy of the model. As per this technique, if the $\mathrm{F}-$ ratio values of the developed models do not exceed the standard tabulated values for a desired level of confidence (95\%) and the calculated $R$ - ratio values of the developed model exceed the standard values for a desired level of confidence (95\%), then the models are said to be adequate within the confidence limit (Kannan and Yoganath, 2010; Palani and Murugan, 2007). These conditions were satisfied for the developed models. The values are shown in Table 5. From the developed models it can be seen that $R$ value is less and $F$ value is greater. So adequacy conditions are satisfied.

\section{VALIDATION OF MODELS}

To test the accuracy of the models in actual application, conformity test were conducted by assigning different values for process variables within their working limits but different from design matrix. 
Table 2. Welding parameters and their levels.

\begin{tabular}{lccccccc}
\hline \multirow{2}{*}{ Parameters } & \multicolumn{7}{c}{ Factor levels } \\
\cline { 2 - 8 } & Unit & Notation & $\mathbf{- 2}$ & $\mathbf{- 1}$ & $\mathbf{0}$ & $\mathbf{1}$ & $\mathbf{2}$ \\
\hline Welding current & $\mathrm{A}$ & 1 & 200 & 225 & 250 & 275 & 300 \\
Welding speed & $\mathrm{mm} / \mathrm{min}$ & $\mathrm{S}$ & 150 & 158 & 166 & 174 & 182 \\
Contact tip to work distance & $\mathrm{mm}$ & $\mathrm{N}$ & 10 & 14 & 18 & 22 & 26 \\
Welding gun angle & Degree & $\mathrm{T}$ & 70 & 80 & 90 & 100 & 110 \\
Pinch & - & $\mathrm{Ac}$ & -10 & -5 & 0 & 5 & 10 \\
\hline
\end{tabular}

Table 3. Design matrix.

\begin{tabular}{|c|c|c|c|c|c|}
\hline \multirow{2}{*}{ Trial number } & \multicolumn{5}{|c|}{ Design matrix } \\
\hline & 1 & $S$ & $\mathbf{N}$ & $\mathbf{T}$ & Ac \\
\hline 1 & -1 & -1 & -1 & -1 & 1 \\
\hline 2 & 1 & -1 & -1 & -1 & -1 \\
\hline 3 & -1 & 1 & -1 & -1 & -1 \\
\hline 4 & 1 & 1 & -1 & -1 & 1 \\
\hline 5 & -1 & -1 & 1 & -1 & -1 \\
\hline 6 & 1 & -1 & 1 & -1 & 1 \\
\hline 7 & -1 & 1 & 1 & -1 & 1 \\
\hline 8 & 1 & 1 & 1 & -1 & -1 \\
\hline 9 & -1 & -1 & -1 & 1 & -1 \\
\hline 10 & 1 & -1 & -1 & 1 & 1 \\
\hline 11 & -1 & 1 & -1 & 1 & 1 \\
\hline 12 & 1 & 1 & -1 & 1 & -1 \\
\hline 13 & -1 & -1 & 1 & 1 & 1 \\
\hline 14 & 1 & -1 & 1 & 1 & -1 \\
\hline 15 & -1 & 1 & 1 & 1 & -1 \\
\hline 16 & 1 & 1 & 1 & 1 & 1 \\
\hline 17 & -2 & 0 & 0 & 0 & 0 \\
\hline 18 & 2 & 0 & 0 & 0 & 0 \\
\hline 19 & 0 & -2 & 0 & 0 & 0 \\
\hline 20 & 0 & 2 & 0 & 0 & 0 \\
\hline 21 & 0 & 0 & -2 & 0 & 0 \\
\hline 22 & 0 & 0 & 2 & 0 & 0 \\
\hline 23 & 0 & 0 & 0 & -2 & 0 \\
\hline 24 & 0 & 0 & 0 & 2 & 0 \\
\hline 25 & 0 & 0 & 0 & 0 & -2 \\
\hline 26 & 0 & 0 & 0 & 0 & 2 \\
\hline 27 & 0 & 0 & 0 & 0 & 0 \\
\hline 28 & 0 & 0 & 0 & 0 & 0 \\
\hline 29 & 0 & 0 & 0 & 0 & 0 \\
\hline 30 & 0 & 0 & 0 & 0 & 0 \\
\hline 31 & 0 & 0 & 0 & 0 & 0 \\
\hline 32 & 0 & 0 & 0 & 0 & 0 \\
\hline
\end{tabular}

I - Welding current; S - welding speed; N - contact tip to work distance; T - welding gun angle; Ac - pinch.

Three weld runs were made using different values of welding current, welding speed, contact tip to work distance, welding gun angle and pinch other than what were used in the design matrix. These experiments were conducted to verify regression Equations 


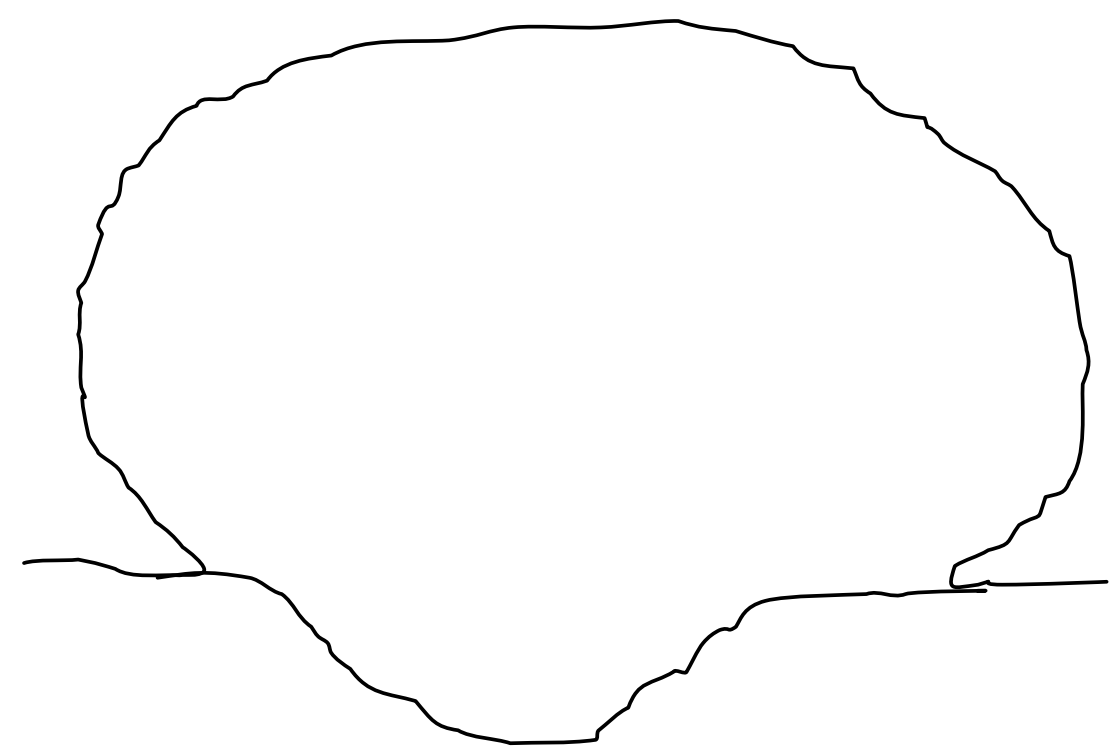

Figure 4. Traced profile of bead geometry.

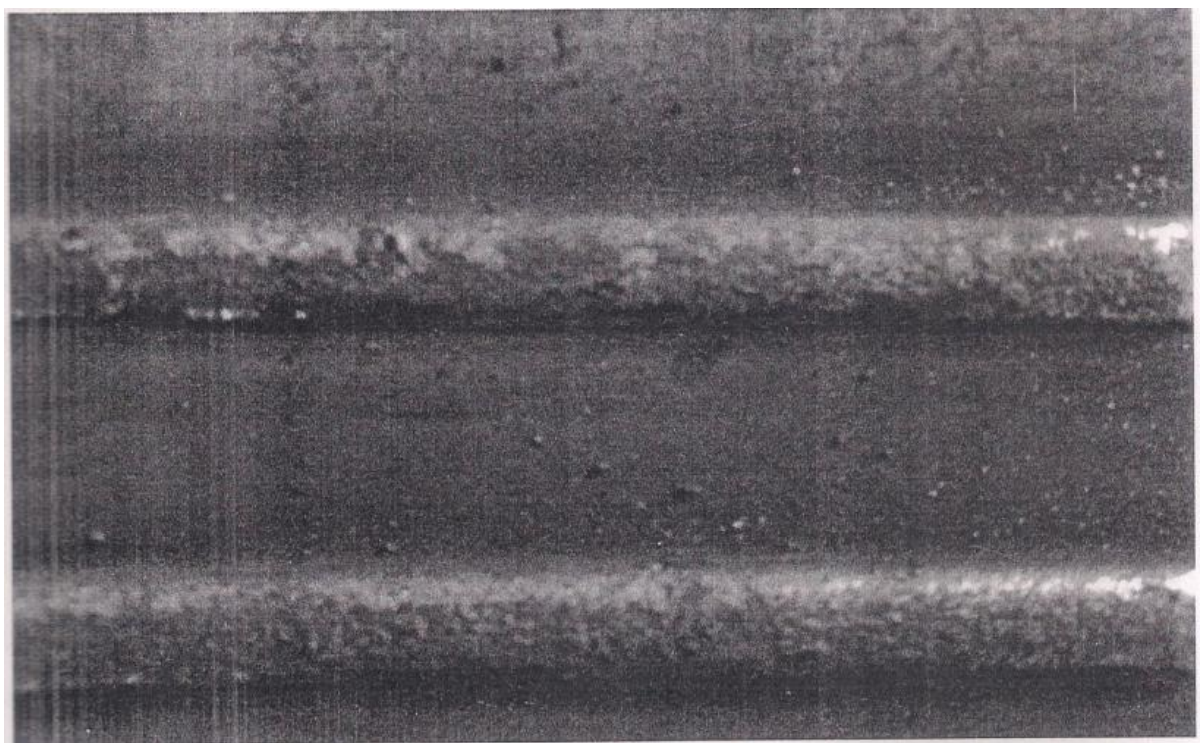

Figure 5. Cladded specimen.

9 to 12 . Specimens were cut from conformity plates and their bead profiles were measured. The percentage of errors calculated using the Equation 13. This is shown in Table 6. It is found that average error is less than $3 \%$ :

Error $=\frac{(\text { Actual value-Predictedvalue }) X 100}{\text { Predicted value }}$

\section{OPTIMIZATION OF DILUTION}

The objective function for dilution which must be minimized was derived from Equation 13. The constraints are shown. MATLAB optimization tool box was used for optimizing problem. The Fmincon function was used for optimization. It uses SQP method for optimization. Sequential quadratic programming methods represents the state of the art in nonlinear programming methods. Based on the works of Biggs, Han and Powell; an SQP method mimics Newton's method for constraint optimization. It is an iterative method of starting from some initial point and converging to a constrained local minimum (Edwin and Kumaanan, 2001). At each iteration, one solves a quadratic program (QP) that models the original nonlinear constrained problem at the current point. The solution to the QP is used as a search direction to find an improving point, which is the next iteration. The iteration is repeated until an optimal solution is found. The SQP solver used in our experiment is fmincon from the MATLAB optimization toolbox. 
Table 4. Design matrix and observed values of clad bead geometry.

\begin{tabular}{|c|c|c|c|c|c|c|c|c|c|}
\hline \multirow{2}{*}{ Trial No } & \multicolumn{5}{|c|}{ Design matrix } & \multicolumn{4}{|c|}{ Bead parameters } \\
\hline & I & $\mathrm{S}$ & $\mathbf{N}$ & $\mathbf{T}$ & Ac & $W(\mathrm{~mm})$ & $P(\mathbf{m m})$ & $R(\mathrm{~mm})$ & D (\%) \\
\hline 1 & -1 & -1 & -1 & -1 & 1 & 6.9743 & 1.67345 & 6.0262 & 10.72091 \\
\hline 2 & 1 & -1 & -1 & -1 & -1 & 7.6549 & 1.9715 & 5.88735 & 12.16746 \\
\hline 3 & -1 & 1 & -1 & -1 & -1 & 6.3456 & 1.6986 & 5.4519 & 12.74552 \\
\hline 4 & 1 & 1 & -1 & -1 & 1 & 7.7635 & 1.739615 & 6.0684 & 10.61078 \\
\hline 5 & -1 & -1 & 1 & -1 & -1 & 7.2683 & 2.443 & 5.72055 & 16.67303 \\
\hline 6 & 1 & -1 & 1 & -1 & 1 & 9.4383 & 2.4905 & 5.9169 & 15.96692 \\
\hline 7 & -1 & 1 & 1 & -1 & -1 & 6.0823 & 2.4672 & 5.49205 & 16.5894 \\
\hline 8 & 1 & 1 & 1 & -1 & -1 & 8.4666 & 2.07365 & 5.9467 & 14.98494 \\
\hline 9 & -1 & -1 & -1 & 1 & -1 & 6.3029 & 1.5809 & 5.9059 & 10.2749 \\
\hline 10 & 1 & -1 & -1 & 1 & 1 & 7.0136 & 1.5662 & 5.9833 & 9.707297 \\
\hline 11 & -1 & 1 & -1 & 1 & 1 & 6.2956 & 1.58605 & 5.5105 & 11.11693 \\
\hline 12 & 1 & 1 & -1 & 1 & -1 & 7.741 & 1.8466 & 5.8752 & 11.4273 \\
\hline 13 & -1 & -1 & 1 & 1 & 1 & 7.3231 & 2.16475 & 5.72095 & 15.29097 \\
\hline 14 & 1 & -1 & 1 & 1 & -1 & 9.6171 & 2.69495 & 6.37445 & 18.54077 \\
\hline 15 & -1 & 1 & 1 & 1 & -1 & 6.6335 & 2.3089 & 5.554 & 17.23138 \\
\hline 16 & 1 & 1 & 1 & 1 & 1 & 10.514 & 2.7298 & 5.4645 & 20.8755 \\
\hline 17 & -2 & 0 & 0 & 0 & 0 & 6.5557 & 1.99045 & 5.80585 & 13.65762 \\
\hline 18 & 2 & 0 & 0 & 0 & 0 & 7.4772 & 2.5737 & 6.65505 & 15.74121 \\
\hline 19 & 0 & -2 & 0 & 0 & 0 & 7.5886 & 2.50455 & 6.4069 & 15.77816 \\
\hline 20 & 0 & 2 & 0 & 0 & 0 & 7.5014 & 2.1842 & 5.6782 & 16.82349 \\
\hline 21 & 0 & 0 & -2 & 0 & 0 & 6.1421 & 1.3752 & 6.0976 & 8.941799 \\
\hline 22 & 0 & 0 & 2 & 0 & 0 & 8.5647 & 3.18536 & 5.63655 & 22.94721 \\
\hline 23 & 0 & 0 & 0 & -2 & 0 & 7.9575 & 2.2018 & 5.8281 & 15.74941 \\
\hline 24 & 0 & 0 & 0 & 2 & 0 & 7.7085 & 1.85885 & 6.07515 & 13.27285 \\
\hline 25 & 0 & 0 & 0 & 0 & -2 & 7.8365 & 2.3577 & 5.74915 & 16.63287 \\
\hline 26 & 0 & 0 & 0 & 0 & 2 & 8.2082 & 2.3658 & 5.99005 & 16.38043 \\
\hline 27 & 0 & 0 & 0 & 0 & 0 & 7.9371 & 2.1362 & 6.0153 & 15.18374 \\
\hline 28 & 0 & 0 & 0 & 0 & 0 & 8.4371 & 2.17145 & 5.69895 & 14.82758 \\
\hline 29 & 0 & 0 & 0 & 0 & 0 & 9.323 & 3.1425 & 5.57595 & 22.8432 \\
\hline 30 & 0 & 0 & 0 & 0 & 0 & 9.2205 & 3.2872 & 5.61485 & 23.6334 \\
\hline 31 & 0 & 0 & 0 & 0 & 0 & 10.059 & 2.86605 & 5.62095 & 21.55264 \\
\hline 32 & 0 & 0 & 0 & 0 & 0 & 8.9953 & 2.72068 & 5.7052 & 19.60811 \\
\hline
\end{tabular}

W - Width; R - reinforcement; W - width; P - penetration; D - dilution \%.

Table 5. Analysis of variance for testing adequacy of the model.

\begin{tabular}{llllllllllll}
\hline \multirow{2}{*}{ Parameter } & 1st order terms & \multicolumn{2}{l}{ 2nd order terms } & \multicolumn{2}{c}{ Lack of fit } & \multicolumn{2}{c}{ Error terms } & F-ratio & \multicolumn{2}{c}{ R-ratio } & Whether model \\
& \cline { 2 - 11 } is adequate \\
\hline SS & DF & SS & DF & SS & DF & SS & DF & & \multicolumn{2}{c}{ Adequate } \\
P & 36.889 & 20 & 6.233 & 11 & 3.513 & 6 & 2.721 & 5 & 1.076 & 3.390 & Adequate \\
R & 7.810 & 20 & 0.404 & 11 & 0.142 & 6 & 0.261 & 5 & 0.454 & 7.472 & Adequate \\
D & 1.921 & 20 & 0.572 & 11 & 0.444 & 6 & 0.128 & 5 & 2.885 & 3.747 & Adequate \\
\hline
\end{tabular}

SS - Sum of squares; DF - degree of freedom; F ratio $(6,5,0.5)=3.40451 ; R$ ratio $(20,5,0.05)=3.20665$.

The objective function selected for optimizing was percentage of dilution, the response variables bead width $(\mathrm{W})$, penetration $(\mathrm{P})$, reinforcement $(R)$ and dilution $(D)$ were given as constraint in their equation. The constrained non linear optimisation is mathematically 
Table 6. Conformity tests.

\begin{tabular}{|c|c|c|c|c|c|c|c|c|c|c|c|c|c|c|c|c|c|}
\hline \multirow{2}{*}{ Test No. } & \multicolumn{5}{|c|}{ Process parameter } & \multicolumn{4}{|c|}{ Actual } & \multicolumn{4}{|c|}{ Predicted } & \multicolumn{4}{|c|}{ Error } \\
\hline & $\mathbf{I}$ & $\mathbf{S}$ & $\mathbf{N}$ & $\mathbf{T}$ & Ac & $\mathbf{W}$ & $\mathbf{H}$ & $\mathbf{R}$ & D & $\mathbf{W}$ & $\mathbf{H}$ & $\mathbf{R}$ & D & $\mathbf{W}$ & $\mathbf{H}$ & $\mathbf{R}$ & D \\
\hline 1 & -1.5 & -1.5 & -1.5 & -1.5 & 1.5 & 6.7895 & 1.4657 & 6.2345 & 10.6874 & 7.8654 & 1.8768 & 7.23456 & 9.9876 & -0.075 & -0.411 & -1.01 & -0.6998 \\
\hline 2 & 1.5 & -1.5 & -1.5 & -1.5 & 1.5 & 7.4765 & 1.67892 & 5.6754 & 11.46784 & 6.9876 & 2.2654 & 6.7896 & 10.7685 & 0.4785 & 0.5765 & -1.11 & 1.693 \\
\hline 3 & -1.5 & 1.5 & -1.5 & -1.5 & 1.5 & 6.6789 & 1.7234 & 5.8765 & 14.9865 & 7.9076 & 1.8796 & 6.8976 & 15.7896 & 1.2387 & -0.156 & -1.02 & -0.9246 \\
\hline
\end{tabular}

Table 7. Existing continuous optimization methods and examples of their implementations.

\begin{tabular}{lll}
\hline Parameters & Examples category & \\
\hline Sequential quadratic programming & Fmincon in Matlab & Local search \\
Quasi Newton & Fminunc in Matlab & Local Search \\
Interior point & LOQO & Local search \\
Nelder-mead direct search & Fmin search in Matlab & Local and global search \\
Simulated annealing & ASA & Global search \\
\hline
\end{tabular}

stated as follows:

\section{Minimize $f(x)$}

Subject to $f(X(1), X(2), X(3), X(4), X(5))<0$

Optimization algorithm is becoming popular in engineering activities. They are extensively used in engineering problems where emphasizing maximizing or minimizing a goal. Importance of optimization is:

i) Reducing wastage of material money and processing time.

ii) Decreases the fatigue of worker.

iii) Increased productivity.

iv) Satisfaction of employees and thereby increase of employee morale.

Fmincon algorithms are nowadays popular tool in optimizing. Table 7 shows the existing optimization methods and their implementation. The aim of the study is to find the optimum adjusts for welding current, welding speed, pinch, welding angle and contact to tip distance. Objective function selected for optimization was percentage of dilution. The process parameters and their notation used in writing the programme in MATLAB 7 software are given as follows (Siva et al., 2009; Mostafa and Khajavi, 2006):

$X(1)=$ Welding current (I) in Amps.

$X(2)=$ Welding speed $(S)$ in $\mathrm{mm} / \mathrm{min}$

$X(3)=$ Contact to work piece distance $(\mathrm{N})$ in $\mathrm{mm}$.

$X(4)=$ Welding gun angle $(T)$ in degree

$X(5)=$ Pinch $(A c)$.

Objective function for percentage of dilution which must be minimized was derived from Equation 9 to 12. The constants of welding parameters are given in Table 2.

Subjected to bounds (Godfrey et al., 2007; Kim et al., 1996):

$200 \leq X(1) \leq 300$
$150 \leq X(2) \leq 182$

$10 \leq X(3) \leq 26$

$70 \leq X(4) \leq 110$

$-10 \leq X(5) \leq 10$

\section{Objective function}

$f(x)=19.75+0.325^{*} x(1)+0.347^{*} x(2)+3.141^{*} x(3)-$ $0.039^{*} x(4)-0.153^{*} x(5)-1.324^{*} x(1)^{\wedge} 2-0.923^{*} x(2)^{\wedge} 2-$ $1.012^{*} x(3)^{\wedge} 2-1.371^{*} x(4)^{\wedge} 2-0.872^{*} x(5)^{\wedge} 2 \quad-$ $0.200^{*} x(1)^{\star} x(2)+0.346^{*} x(1)^{\star} x(3)+0.602^{*} x(1)^{*} x(4)+$ $0.203^{*} x(1)^{\star} x(5)+0.011^{*} x(2)^{*} x(3)+0.465^{\star} x(2)^{\star} x(4)+$ $0.548^{*} x(2)^{*} x(5)+0.715^{*} x(3)^{*} x(4)+0.360^{*} x(3)^{*} x(5)+$ $0.137^{*} \times(4)^{\star} \times(5)$

(which is the percentage of dilution).

\section{Constraint equations}

$W=\left(8.923+0.701^{\star} x(1)+0.388^{*} x(2)+0.587^{\star} x(3)+0.040^{\star} x(4)\right.$ $+0.088^{\star} x(5)-0.423^{\star} x(1)^{\wedge} 2-0.291^{\star} x(2)^{\wedge} 20.338^{*} x(3)^{\wedge} 2$ 
Table 8. Optimal process parameters.

\begin{tabular}{lc}
\hline Parameter & Range \\
\hline Welding current (I) & $200 \mathrm{amps}$ \\
Welding speed (S) & $155 \mathrm{~mm} / \mathrm{min}$ \\
Contact tip to work distance(N) & $10 \mathrm{~mm}$ \\
Welding gun angle (T) & $86^{\circ}$ \\
Pinch (Ac) & -5 \\
\hline
\end{tabular}

Table 9. Optimal bead parameters.

\begin{tabular}{lc}
\hline Dilution $(\mathrm{D})$ & $10.9828 \%$ \\
Clad bead width $(\mathrm{W})$ & $6.952 \mathrm{~mm}$ \\
Penetration $(\mathrm{P})$ & $2.017 \mathrm{~mm}$ \\
Height of reinforcement $(\mathrm{R})$ & $5.11 \mathrm{~mm}$ \\
\hline
\end{tabular}

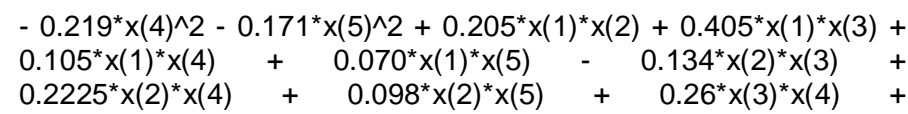

$\left.0.086^{*} x(3)^{\star} x(5)+0.12^{\star} x(4)^{\star} x(5)\right)-3$

[clad bead width (W) lower limit],

$P=\left(2.735+0.098^{*} x(1)-0.032^{*} x(2)+0.389^{*} x(3)-0.032^{*} x(4)-\right.$ $0.008^{*} x(5)-0.124^{\star} x(1)^{\wedge} 2-0.109^{*} x(2)^{\wedge} 2-0.125^{\star} x(3)^{\wedge} 2-$ $0.187^{\star} x(4)^{\wedge} 2-0.104^{\star} x(5)^{\wedge} 2-0.33^{*} x(1)^{\star} x(2)+0.001^{*} x(1)^{\star} x(3)+$ $0.075^{\star} x(1)^{\star} x(4)+0.005^{\star} x(1)^{\star} x(5)-0.018^{\star} x(2)^{\star} x(3)+0.066^{\star} x(2)^{\star} x(4)$ $+0.087^{*} x(2)^{\star} x(5)+0.058^{*} x(3)^{\star} x(4)+0.054^{*} x(3)^{*} x(5)$ $\left.0.036^{*} x(4)^{*} x(5)\right)-3$

[depth of penetration $(\mathrm{P})$ upper limit].

$P=\left(2.735+0.098^{*} x(1)-0.032^{*} x(2)+0.389^{*} x(3)-0.032^{*} x(4)-\right.$ $0.008^{\star} x(5)-0.124^{\star} x(1)^{\wedge} 2-0.109^{\star} x(2)^{\wedge} 2-0.125^{\star} x(3)^{\wedge} 2-$ $0.187^{\star} x(4)^{\wedge} 2-0.104^{*} x(5)^{\wedge} 2-0.33^{\star} x(1)^{\star} x(2)+0.001^{*} x(1)^{*} x(3)+$ $0.075^{\star} x(1)^{\star} x(4)+0.005^{\star} x(1)^{*} x(5)-0.018^{*} x(2)^{*} x(3)+0.066^{*} x(2)^{*} x(4)$ $+0.087^{*} x(2)^{\star} x(5)+0.058^{*} x(3)^{\star} x(4)+0.054^{*} x(3)^{*} x(5)$ $\left.0.036^{*} x(4)^{*} x(5)\right)+2$

[depth of penetration $(\mathrm{P})$ lower limit].

$W=\left(8.923+0.701^{*} x(1)+0.388^{*} x(2)+0.587^{\star} x(3)+0.040^{\star} x(4)+\right.$ $0.088^{*} \times(5) \quad-0.423^{*} x(1)^{\wedge} 2 \quad-0.291^{*} x(2)^{\wedge} 2 \quad-$ $0.338^{\star} x(3)^{\wedge} 20.219^{\star} x(4)^{\wedge} 20.171^{\star} x(5)^{\wedge} 2+0.205^{\star} x(1)^{\star} x(2)+$ $0.405^{\star} x(1)^{\star} x(3)+0.105^{\star} x(1)^{\star} x(4)+0.070^{\star} x(1)^{\star} x(5)-0.134^{\star} x(2)^{\star} x(3)$ $+0.225^{\star} x(2)^{\star} x(4)+0.098^{*} x(2)^{\star} x(5)+0.26^{*} x(3)^{\star} x(4)+$ $\left.0.086^{\star} x(3)^{\star} x(5)+0.012^{\star} x(4)^{\star} x(5)\right)-10$

[clad bead width (W) upper limit).

$R=\left(5.752+0.160^{\star} x(1)-0.151^{*} x(2)-0.060^{*} x(3)+0.016^{*} x(4)-\right.$ $0.002^{\star} x(5)+0.084^{*} x(1)^{\wedge} 2+0.037^{\star} x(2)^{\wedge} 2-0.0006^{\star} x(3)^{\wedge} 2+$ $0.015^{\star} x(4)^{\wedge} 2-0.006^{\star} x(5)^{\wedge} 2+0.035^{\star} x(1)^{\star} x(2)+0.018^{\star} x(1)^{\star} x(3)-$ $0.008^{*} x(1)^{\star} x(4)-0.048^{*} x(1)^{\star} x(5)-0.024^{*} x(2)^{*} x(3)-0.062^{*} x(2)^{*} x(4)$ $-0.003^{*} x(2)^{*} x(5)+0.012^{*} x(3)^{*} x(4)-0.092^{*} x(3)^{*} x(5)$ $\left.0.095^{\star} x(4)^{\star} x(5)\right)-6$

[height of reinforcement $(R)$ lower limit).

$R=\left(5.752+0.160^{*} x(1)-0.151^{*} x(2)-0.060^{*} x(3)+0.016^{*} x(4)-\right.$ $0.002^{\star} x(5)+0.084^{\star} x(1)^{\wedge} 2+0.037^{\star} x(2)^{\wedge} 2-0.0006^{\star} x(3)^{\wedge} 2+$ $0.015^{\star} x(4)^{\wedge} 2-0.006^{\star} x(5)^{\wedge} 2+0.035^{\star} x(1)^{\star} x(2)+0.018^{\star} x(1)^{\star} x(3)-$ $0.008^{\star} x(1)^{\star} X(4)-0.048^{\star} x(1)^{\star} x(5)-0.024^{\star} x(2)^{\star} x(3)-0.062^{\star} x(2)^{*} x(4)$ $-0.003^{*} x(2)^{*} x(5)+0.012^{*} x(3)^{*} x(4)-0.092^{*} x(3)^{*} x(5)$ $\left.0.095^{*} x(4)^{*} x(5)\right)+6$

[heights of reinforcement $(R)$ upper limit],

$f(x)-3$

$-f(x)+8$

(dilution upper and lower limit),

$x(1), x(2), x(3), x(4), x(5) \leq 2$;

$x(1), x(2), x(3), x(4), x(5) \geq-2$;

MATLAB program in Femincon function was used for optimizing the problem. The program was written and constraints bounds were applied. The minimum percentage of dilution obtained from the results obtained running the Fmincon program is as follows (Farhad and Mehdi, 2010; Sahoo, 2011; Sathiya and Abdul, 2010):

$X(1)=$ Welding current $(I)=1.873$

$X(2)=$ Welding speed $(S)=-0.9801$

$X(3)=$ Contact to work piece distance $(N)=-1.0433$

$X(4)=$ Welding gun angle $(T)=1.8922$.

$X(5)=$ Pinch $(A c)=-1.8920$.

\section{Optimal process and bead parameters}

Tables 8 and 9 shows optimal process and bead parameters, respectively.

\section{RESULTS AND DISCUSSION}

1) A five level five factor full factorial design matrix based on central composite rotatable design technique was used for the mathematical development of model to predict clad bead geometry of austenitic stainless steel deposited by GMAW.

2) From Figure 6, it is apparent that bead width increases gradually for a rise of $S$ from lower limit of -2 to centre point 0 and increases slightly as $S$ increases slightly while the other factors kept constant. This is due to the fact that welding current increases, results in an increased power per unit length of weld bead. Higher current density was due to increase in $\mathrm{S}$, causing large volume of base metal to melt and so deeper penetration. An increase in welding current with other variables constant result in an increase in penetration and bead width with increased disposition rate so increases weld bed size.

3) In cladding by a welding process, clad bead geometry is very important for economising the material. This study effectively used mathematical models to predict weld bead geometry.

4) Figures 6, 7, 8, 9, 10 and 11 show interaction effects of various parameters on bead geometry. From Figure 7 , it is shown that penetration increases with welding current up to zero and then decreases up to 2 when welding speed remains constant. Figure 8 shows when welding 


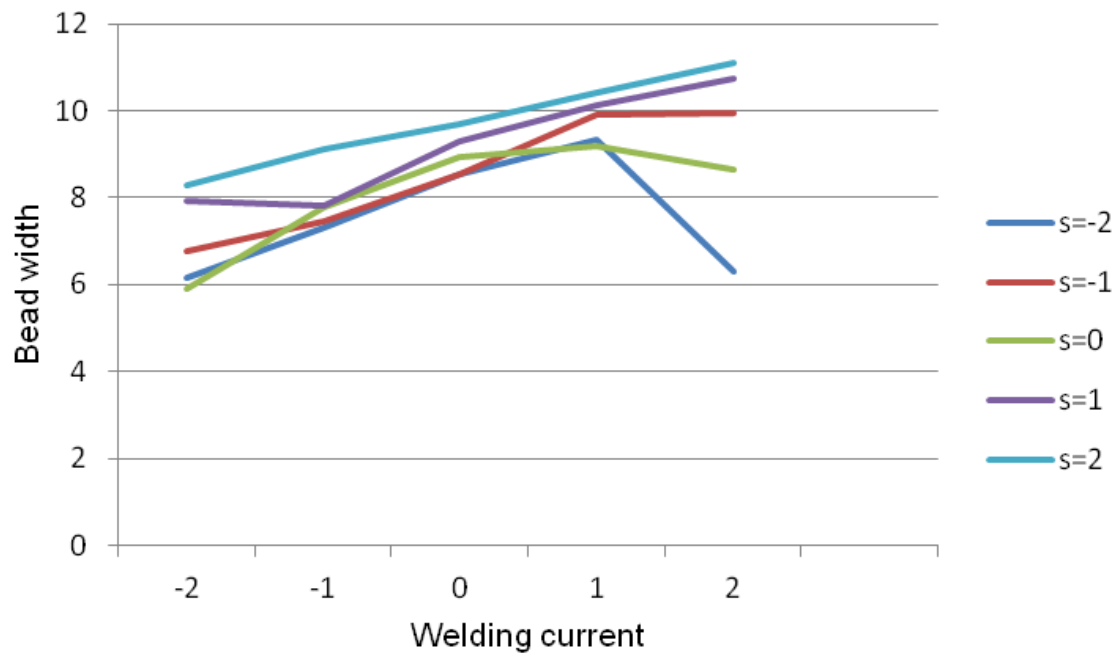

Figure 6. Interaction effect of welding current and welding speed on bead width.

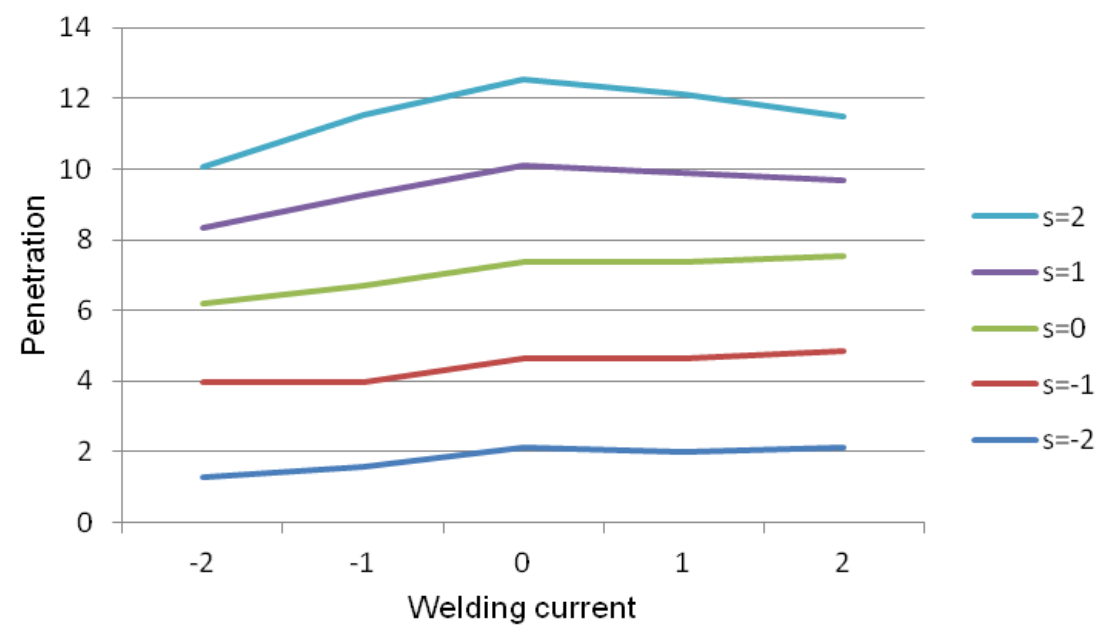

Figure 7. Interaction effect of welding current and welding speed on penetration.

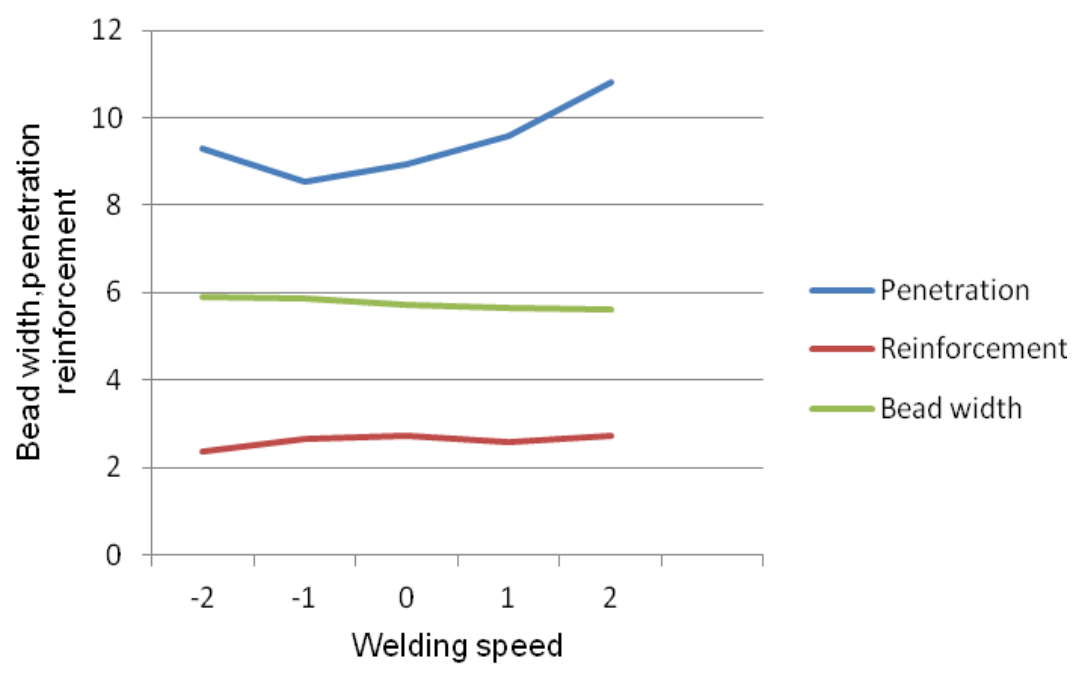

Figure 8. Direct effect of welding speed on bead parameters. 


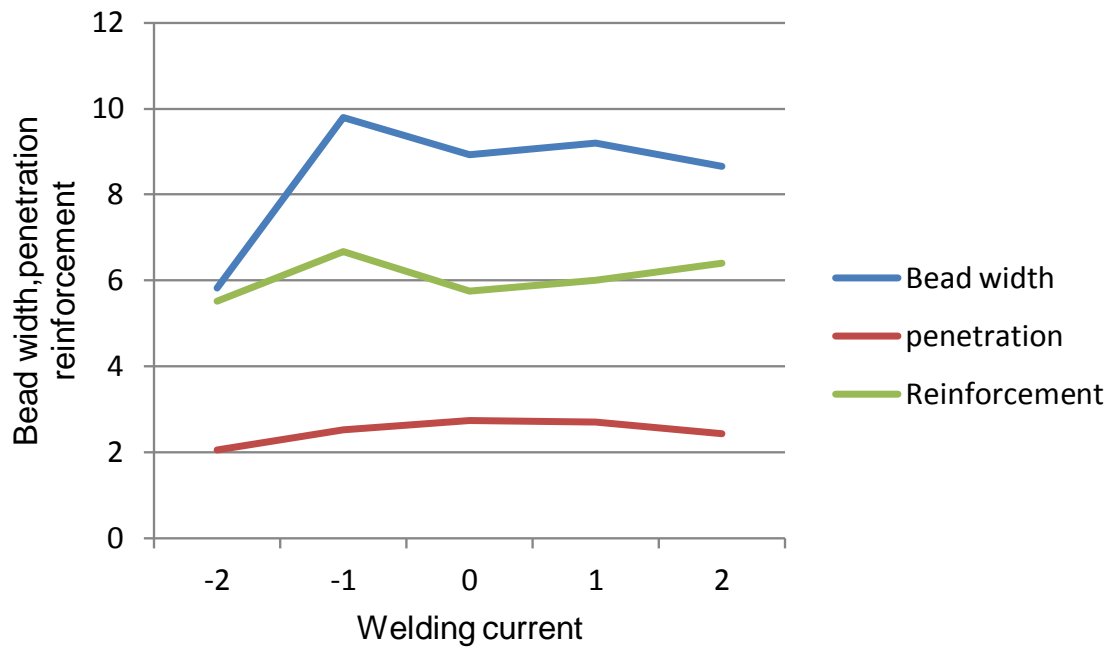

Figure 9. Direct effect of welding current on bead parameters.

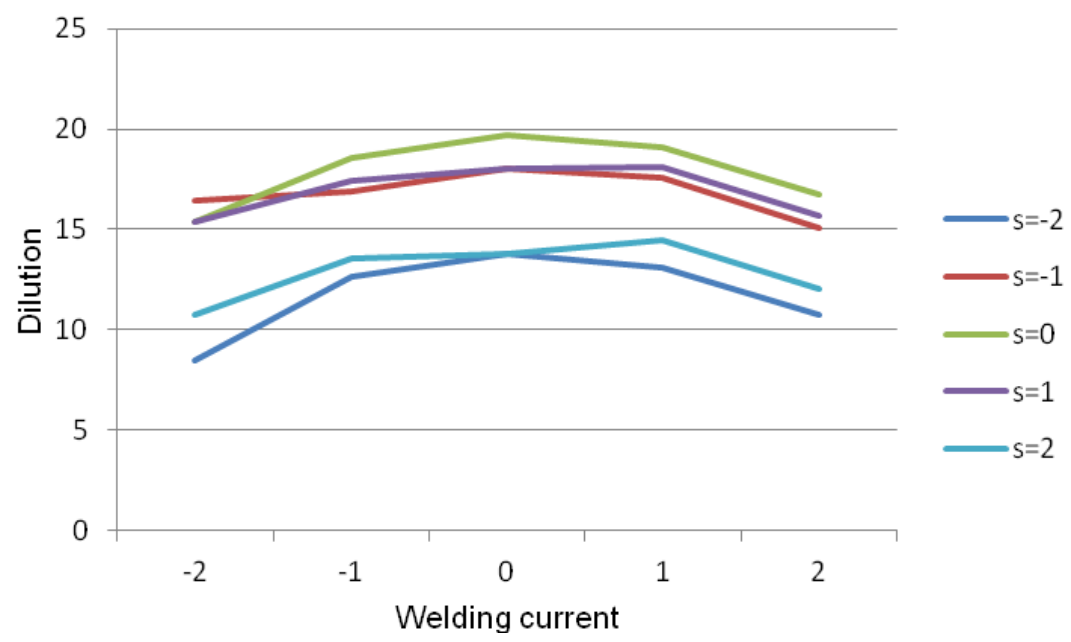

Figure 10. Interaction of welding current welding speed on dilution.

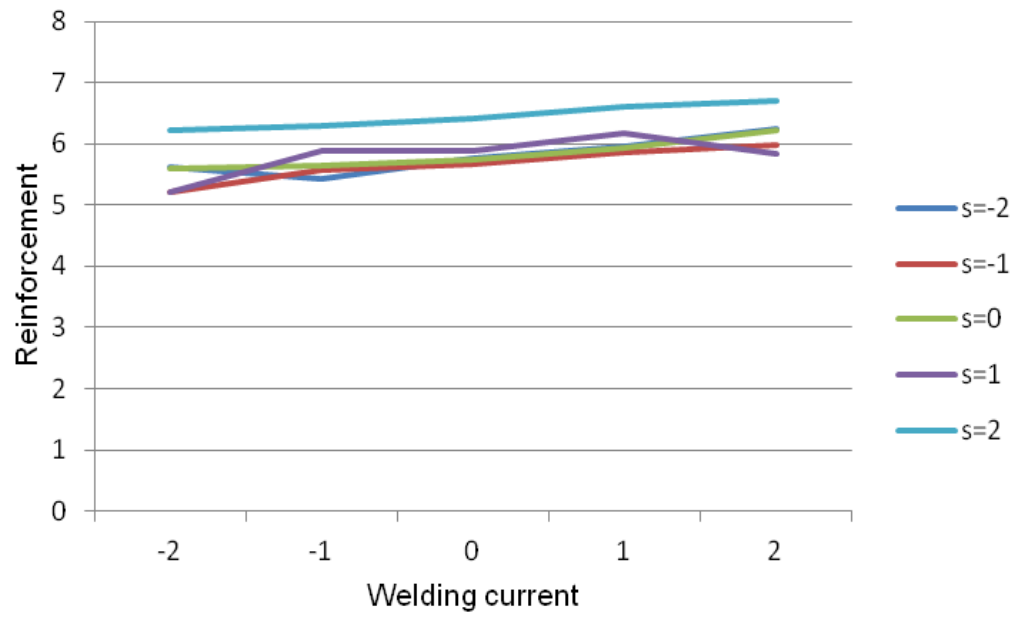

Figure 11. Interaction of welding current welding speed on reinforcement. 
speed increases at first penetration decreases and then increases. But bead width almost remains constant. Reinforcement slightly increases with welding speed.

\section{Conclusions}

Based on the aforementioned study, it can be observed that the developed model can be used to predict clad bead geometry within the applied limits of process parameters. This method of predicting process parameters can be used to get optimum process parameters to get good bead geometry. In the case of any cladding process, bead geometry plays an important role in determining the properties of the surface exposed to hostile environments and reducing cost of manufacturing. The optimization method can also be used to find optimum welding conditions for minimum dilution. The statistical method for modelling and optimization method used have found increasing applications in industry because of its easiness and economically cheap. The method described in this paper for optimizing percentage of dilution eliminates the need for performing experiments based on conventional trial and error method which is time consuming and economically not justifiable. It is more efficient compared to other conventional methods.

\section{ACKNOWLEDGEMENT}

Authors sincerely acknowledge the help and facilities extended to them by the Department of Mechanical Engineering, SVS College of Engineering, Coimbatore, India.

\section{REFERENCES}

Cochran WG, Coxz GM (1987). Experimental Design. New York, John Wiley \& Sons, p. 130.

Edwin R, Dhas J, Kumaanan S (2001). Optimization of process parameters of submerged arc welding using non conventional techniques. Appl. Soft Comput. 11:5198-5204

Farhad K, Mehdi H (2010). A New Approach for Predicting and Optimising Weld Bead Geometry in GMAW. Int. J. Mech. Syst. Sci. Eng. 2(2) 138-142.

Ghosh PK, Gupta PC, Goyal VK (1998). Stainless steel cladding of structural steel plate using the pulsed current GMAW process. Welding, p. 314.

Giridharan PK, Murugan N (2009). Optimization of pulsed GTA welding process parameters for the welding of AISI $304 \mathrm{~L}$ stainless steel. Int. J. Adv. Manuf. Technol. 40:478-489.

Godfrey CO, Paulo D, Carlos O, Cardoso A (2007). Prediction of clad angle in laser cladding by powder using response surface methodology and scatter search. Optics Laser Technol. 139:11301134.

Gunaraj V, Murugan N (1999) .Prediction and comparison of the area of the heat effected zone for the bead on plate and bead on joint in SAW of pipes. J. Mater. Process. Technol. 95:246-261.

Gunaraj V, Murugan N (2005). Prediction and control of weld bead geometry and shape relationships in submerged arc welding of pipes. J. Mater. Process Technol. 168:478-487.
Kannan T, Murugan N (2006). Effect of flux cored arc welding process parameters on duplex stainless steel clad quality. J. Mater. Process. Technol. 176:230-239.

Kannan T, Murugn N (2006). Prediction of ferrite number of duplex stainless steel clad metals using RSM. Weld. J. 124:91-99.

Kannan T, Yoganath J (2010). Effect of process parameters on clad bead geometry and shape relationships of stainless steel cladding deposited by GMAW. Int. J. Manuf. Technol. 47:1083-1095.

Kim IS, Basu A, Siores E (1996). Mathematical Models for control of weld weed penetration in the GMAW Process. Int. J. Adv. Manuf. Technol. 12:303-401.

Kim IS, Son KJ, Yang YS, Yaragada PKDV (2003). Sensitivity analysis for process parameters in GMA welding process using factorial design method. Int. J. Mach. Tools Manuf. 43:763-769. May-June.

Montgomery DC (2003). Design and analysis of Experiments. John Wiley \& Sons (ASIA) Pvt. Ltd.

Mostafa NB, Khajavi MN (2006). Optimization of welding parameters for weld penetration in FCAW. J. Achiev. Mater. Manuf. Eng. 16:1-2.

Palani PK, Murugan N (2007). Optimization of weld bead geometry for stainless steel claddings deposited by FCAW. J. Mater. Process. Technol. 190:291-299.

Sahoo P (2011). Optimization of turning parameters for surface roughness using RSM and GA. Adv. Prod. Eng. Manage. 3:197-208

Sathiya P, Abdul JMY (2010). Green based Taughi method for optimization of bead geometry in laser bead on plate welding. Adv. Prod. Eng. Manag. 4:225-234.

Serdar K, Abdullah S (2008). Sensitivity analysis of submerged arc welding process parameters. J. Mater. Process. Technol. 202:500507.

Siva K, Murugan N, Logesh R (2009). Optimisation of Weld Bead Geometry in Plasma Transferred Arc Hard faced Austenitic Stainless Steel Plates using Genetic Algorithm. Int. J. Adv. Manuf. Technol. 4:24-30. 